\title{
Garlic Extract (Allicin) Improves the Proliferation of Endothelial Progenitor Cell from Patients with Stable Coronary Artery Disease
}

\author{
Yudi Her Oktaviono*, Budi Susetyo Pikir, Fatimah Alzahra, Makhyan Jibril Al-Farabi, Alisia Yuana Putri \\ Department of Cardiology and Vascular Medicine, Faculty of Medicine, Dr. Soetomo General Hospital, Universitas Airlangga, \\ Surabaya, Indonesia
}

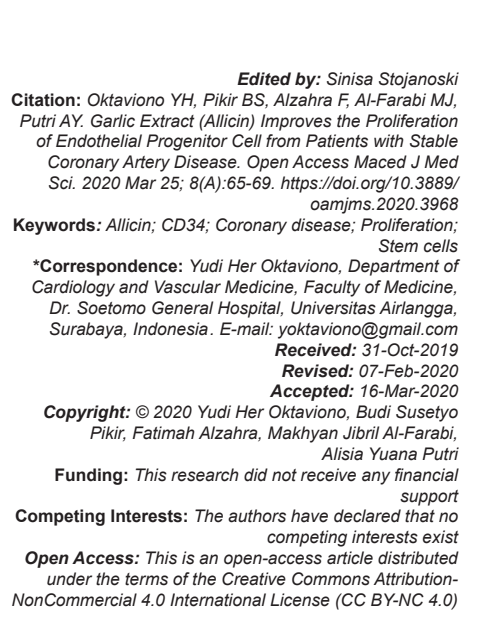

Abstract

BACKGROUND: The reduced number and function of endothelial progenitor cell (EPC) in stable coronary artery disease (SCAD) patients aggravate endothelial dysfunction and inhibit neovascularization, thus lead to atherosclerosis. Garlic is currently believed to increase the number and function of EPC

AIM: Therefore, this in vitro study was conducted to analyze the effect of garlic extract (allicin) on the proliferation of EPC in patients with SCAD.

METHODS: Mononuclear cells were isolated from peripheral blood of eight SCAD patients and cultured on colonyforming unit (CFU)-Hill medium for 3 days. Samples were divided into two groups: Group treated with allicin and control group. The treatment group was then divided into three subgroups which received 10, 50, and $100 \mathrm{mg}$ $\mathrm{ml}$ of doses and incubated for $48 \mathrm{~h}$. EPC proliferation was assessed using 3-(4,5-dimethylthiazol-2-yl)-2,5diphenyltetrazolium bromide (MTT) cell proliferation assay. Immunohistochemical method of CD34+ was performed for EPC identification. Data were analyzed using independent t-test and ANOVA.

RESULTS: MTT assay showed a significant increase in EPC proliferation in the allicin group compared to the contro group $(0.2811 \pm 0.008$ vs. $0.194 \pm 0.151, p<0.05)$ and significant improvements were observed in each dose increment. CFU-Hill quantification shows the addition of EPC colony in high-dose allicin. Immunohistochemical method shows positive CD34+ expression.

CONCLUSION: Allicin increases EPC proliferation dose-dependently from peripheral blood of SCAD patients.

\section{Introduction}

Coronary artery disease $(C A D)$ is still a major health problem throughout the world. This disease causes a decrease in the quality of life of sufferers and is the most common cause of death from heart disease. Until now, based on the Global Burden of Disease Study, an estimated 7.2 million people worldwide die every year due to CHD [1].

Endothelial progenitor cell (EPC) has a role in the process of atherosclerosis at each stage where this process is the pathogenesis of CAD. A decrease in the number and function of EPC begins when various kinds of classic risk factors for atherosclerosis appear. This reduced amount and function of EPC will aggravate existing conditions of endothelial dysfunction, inhibit the collateral formation, and fail to compensate for severe stenosis. This is probably the cause of high rates of major cardiovascular events in patients with low EPC numbers and functions regardless of the severity of CAD [2]. EPC also plays an important role in the angioplasty process. Patients with intracoronary stents need a rapid reendothelialization process to prevent the occurrence of in-stent thrombosis and the development of neointima. This is proven by the occurrence of restenosis in patients with low EPC levels [3].

Various trials have been conducted to increase the number and function of EPC. Garlic is a natural component that is currently believed to prevent and treat cardiovascular disease. Garlic works as an antioxidant that increases the production of nitric oxide (NO) and hydrogen sulfide $\left(\mathrm{H}_{2} \mathrm{~S}\right)$ which can cause vasodilation and improve endothelial function [4]. Garlic also has the ability to inhibit the activity of angiotensin-converting enzymes so that it can reduce blood pressure [5]. The organosulfur component contained in garlic is also able to prevent oxidation of low-density lipoprotein which is responsible for the process of atherosclerosis, which can reduce the number and function of EPC. In some literature, it is said that garlic can inhibit abnormal cell growth that has the potential for malignancy. However, in cells which have properties as precursors, it is said that garlic can increase the number of these cells either through increased proliferation or through inhibition of apoptosis. However, it is still unknown whether the nature of the trigger for apoptosis or cell proliferation from garlic is related to the size of the dose or not, hence the need for further investigation [6]. Therefore, we conducted this study to prove the beneficial effect of 
garlic which can improve neovascularization process in ischemic tissue through its influence on the number and function of EPC.

\section{Methods}

This study was an in vitro exploratory laboratory experimental study using EPCs from the peripheral blood of eight patients with stable CAD (SCAD) using a "posttest-only control group design." This laboratory research was conducted at the stem cell laboratory, Institute of Tropical Disease, Airlangga University for 4 months period (January 2017-April 2017). The sample was peripheral blood EPC isolated from eight stable SCAD patients taken by purposive sampling. The inclusion criteria of the subjects were male who showed stable symptoms of angina pectoris, aged 40-59 years, and had stenotic lesions $\geq 50 \%$ left main coronary arteries and $\geq 70 \%$ in one or more other major coronary arteries based on angiography. Subjects with a history of stenting, acute myocardial infarction, diabetes mellitus, smoking, critical limb ischemia, CABG history, and anemia were excluded from the criteria of the study subjects.

Subjects were grouped into a control group which did not get treatment and the group given allicin, which was divided into three subgroups and received 10,50 , and $100 \mathrm{mg} / \mathrm{ml}$ of doses each. Mononuclear cells were isolated from peripheral blood using Ficoll Histopaque and then cultured in the media for 3 days. The treatment was given on the $4^{\text {th }}$ day in the form of adding allicin. Observations of cell responses were carried out 2 days after treatment. The examination includes immunofluorescence using CD34, assessment of EPC proliferation using 3-(4,5-dimethylthiazol-2-yl)-2,5diphenyltetrazolium bromide (MTT) proliferation assay, and quantification of the number of colonies formed. The data obtained were analyzed using the SPSS 20 with inferential statistical analysis and ANOVA statistical tests.

\section{Results}

\section{Patients' characteristics}

The subjects of this study were eight blood samples, whose basic characteristics are shown in Table 1. The average age of subjects was $54.5 \pm 4.31$ years, with the youngest age of 48 years and the oldest age of 59 years. Cardiovascular risk factors obtained in the study subjects were dyslipidemia and hypertension, where all subjects received antihypertensive drugs and anti-lipid statins.
Table 1: Demographic and baseline patient characteristics

\begin{tabular}{ll}
\hline Variable & Mean $\pm \mathrm{SD}$ \\
\hline Age (years) & $54.5 \pm 4.31$ \\
Systolic blood pressure $(\mathrm{mmHg})$ & $137.5 \pm 24.35$ \\
Diastolic blood pressure $(\mathrm{mmHg})$ & $80 \pm 7.56$ \\
Heart rate (beat $/ \mathrm{min})$ & $86 \pm 8.68$ \\
Body mass index $\left(\mathrm{kg} / \mathrm{m}^{2}\right)$ & $25.39 \pm 2.13$ \\
Total cholesterol $(\mathrm{mg} / \mathrm{dL})$ & $200.5 \pm 74.75$ \\
LDL $(\mathrm{mg} / \mathrm{dL})$ & $145 \pm 61.11$ \\
Triglycerides $(\mathrm{mg} / \mathrm{dL})$ & $97 \pm 11.64$ \\
HDL $(\mathrm{mg} / \mathrm{dL})$ & $35 \pm 7.64$ \\
Ejection fraction left ventricle $(\%)$ & $53.5 \pm 4.11$ \\
\hline LDL: Low-density lipoprotein, HDL: High-density lipoprotein, SD: Standard deviation. &
\end{tabular}

\section{Comparison of EPC proliferation between} the allicin and control groups

EPC proliferation was calculated using the MTT method and the cell absorbance results in optical density. Then, the data normality test was carried out from the effects of EPC proliferation calculations in all treatment and control groups using the KolmogorovSmirnov statistical test with the results of all data distributed normally. The data were then analyzed to determine the differences between the allicin group with a dose of $50 \mu \mathrm{g} / \mathrm{ml}$ (X2) and the control group (C) using the two samples t-test.

EPC proliferation in the group that received allicin was higher than the control group, which was $0.2811 \pm 0.008$ compared to $0.194 \pm 0.151$. This result shows an increase in EPC proliferation with the administration of allicin. Statistical data analysis using the two-sample independent t-test was used to observe differences in the two groups. There was a significant difference in the EPC proliferation between the allicin groups and control groups $(p=0.000)$.

\section{Differences in EPC proliferation in allicin} with low, medium, and high doses

The differences in EPC proliferation between the groups given low-dose allicin (X1), medium (X2), and high (X3) extract, as shown in Figure 1.

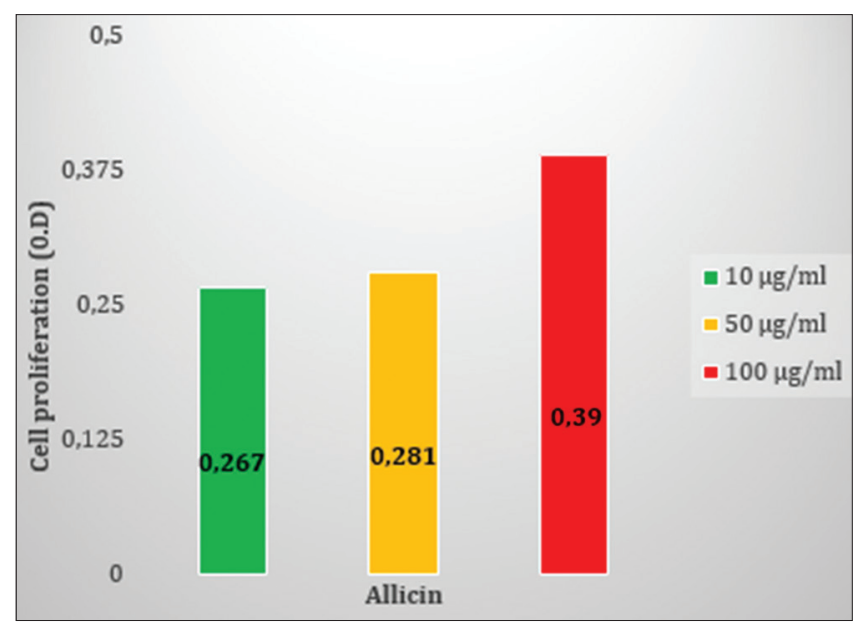

Figure 1: Differences in EPC proliferation in the allicin extract of various doses 
Based on data analysis, there was a difference in EPC proliferation between the groups given low, medium, and high allicin. Statistical tests were performed using ANOVA for EPC proliferation data between the groups and then followed by a significance test using the least significant difference (LSD) test. Obtained EPC proliferation results increased significantly when were given allicin a dose of $50 \mu \mathrm{g} / \mathrm{ml}$ compared with a dose of $10 \mu \mathrm{g} / \mathrm{ml}(p=0.005)$. EPC proliferation also had significant increase by administering allicin dose of $100 \mu \mathrm{g} / \mathrm{ml}$ compared to $50 \mu \mathrm{g} / \mathrm{ml}(p=0.000)$. The proliferation difference between allicin dose of $100 \mu \mathrm{g} / \mathrm{ml}$ was also significant compared to allicin extract with a dose of $10 \mu \mathrm{g} / \mathrm{ml}(p=0.000)$.

Based on data analysis, there was a difference in EPC proliferation between the groups given low, medium, and high allicin. Statistical tests were performed using ANOVA for EPC proliferation data between the groups and then followed by a significance test using the LSD test. Obtained EPC proliferation results increased significantly by giving allicin a dose of $50 \mu \mathrm{g} / \mathrm{ml}$ compared with a dose of $10 \mu \mathrm{g} / \mathrm{ml}$ $(p=0.005)$. EPC proliferation also had significant increase by administering allicin dose of $100 \mu \mathrm{g} / \mathrm{ml}$ compared to $50 \mu \mathrm{g} / \mathrm{ml}(p=0.000)$. The proliferation difference between allicin dose of $100 \mu \mathrm{g} / \mathrm{ml}$ was also significant compared to allicin extract with a dose of $10 \mu \mathrm{g} / \mathrm{ml}(\mathrm{p}=0.000)$.

\section{Examination of colony-forming unit (CFU) in the allicin and control groups}

Observation and calculation of CFU were done to observe and assess the function of the living EPC. After proliferating, EPC tends to form colonies which will later differentiate into endothelial cells. Observations were made in the low-dose, high-dose, and control group of allicin on the $6^{\text {th }}$ day. Figures 2-5 show microscopic images of the control group CFU and allicin.

The number of colonies formed in the control group, the low, medium, and high allicin was different, as listed in Table 2.

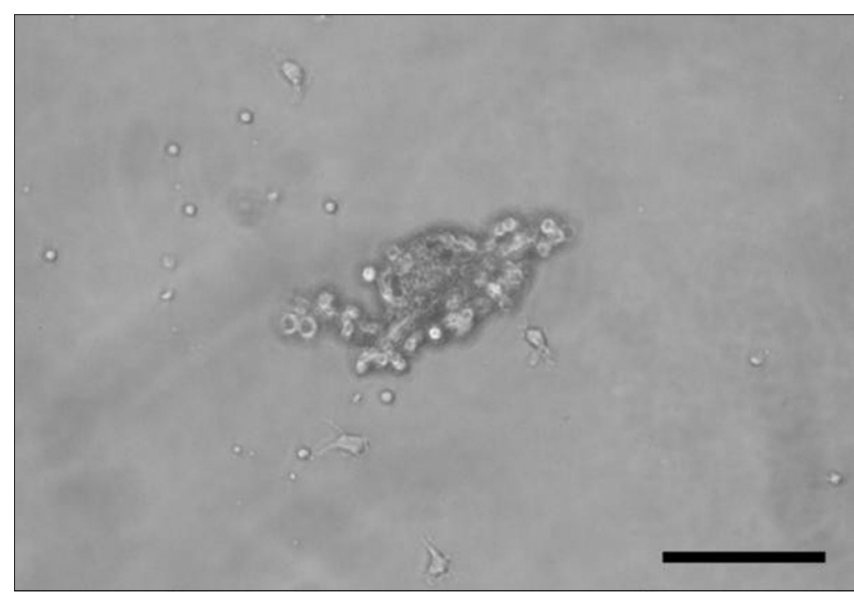

Figure 2: Microscopic picture of the control group colony-forming unit
Table 2: Number of colony-forming unit in the control group and allicin group

\begin{tabular}{lll}
\hline Group & CFU $10 \mu \mathrm{g} / \mathrm{ml}$ & CFU $100 \mu \mathrm{g} / \mathrm{ml}$ \\
\hline Control & 9 & 14 \\
Allicin & 7 & 14 \\
\hline
\end{tabular}

The number of colonies formed in the low-dose garlic extract group was lower than the control group, but at high doses, the number of colonies is higher than the control group.

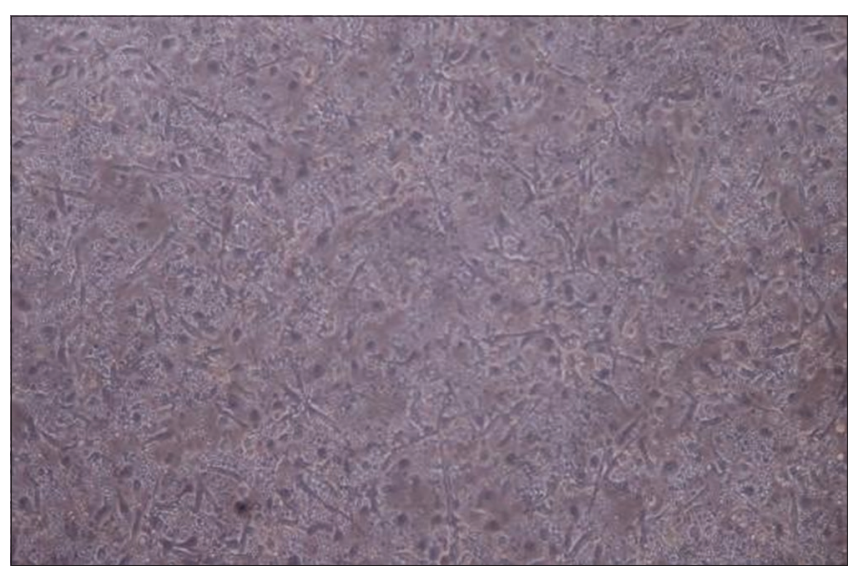

Figure 3: Colony-forming unit microscopic picture of allicin dose of $10 \mu \mathrm{g} / \mathrm{ml}$

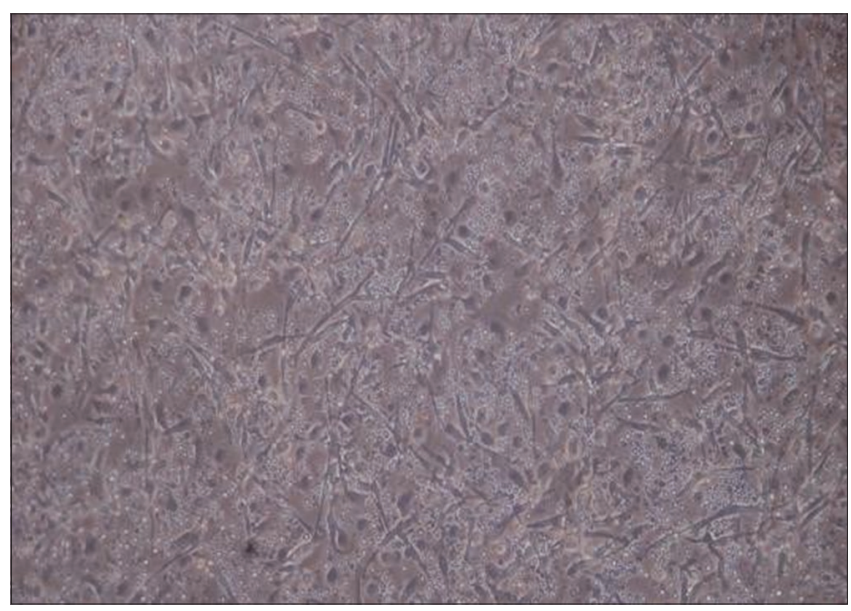

Figure 4: Colony-forming unit microscopic picture of allicin dose of $100 \mu \mathrm{g} / \mathrm{ml}$

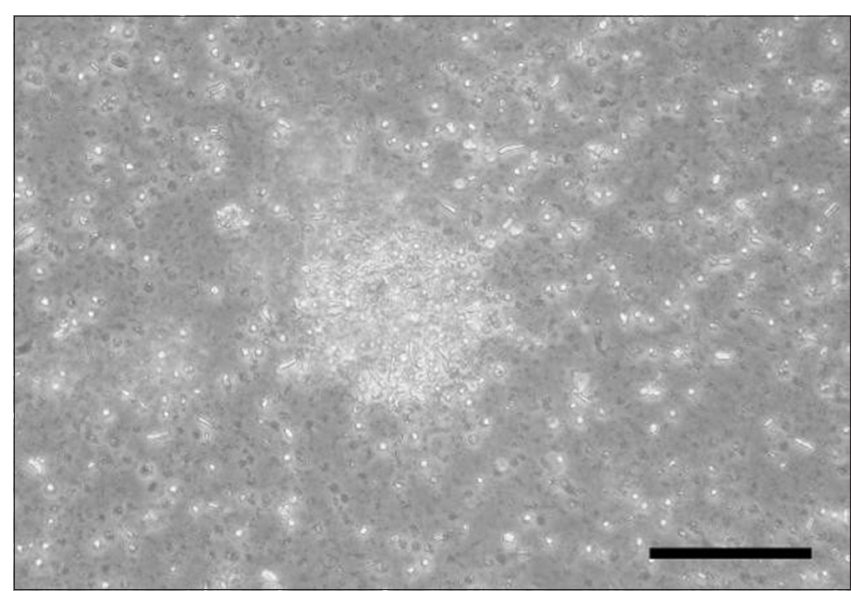

Figure 5: Microscopic picture of EPC colonies at colony-forming unit 


\section{Immunofluorescence examination}

One positive marker for EPC is CD34. This CD34 marker will be expressed on young EPCs that are more mature. The examination was carried out on one of the wells used to grow CFU. After calculating the colony, the preparation was washed using PBS solution and prepared for immunofluorescence examination using CD34. From observations using fluorescence microscopy, CD34 expressions were obtained, which were indicated by the presence of EPC cells that had green fluorescent colors such as Figure 6.

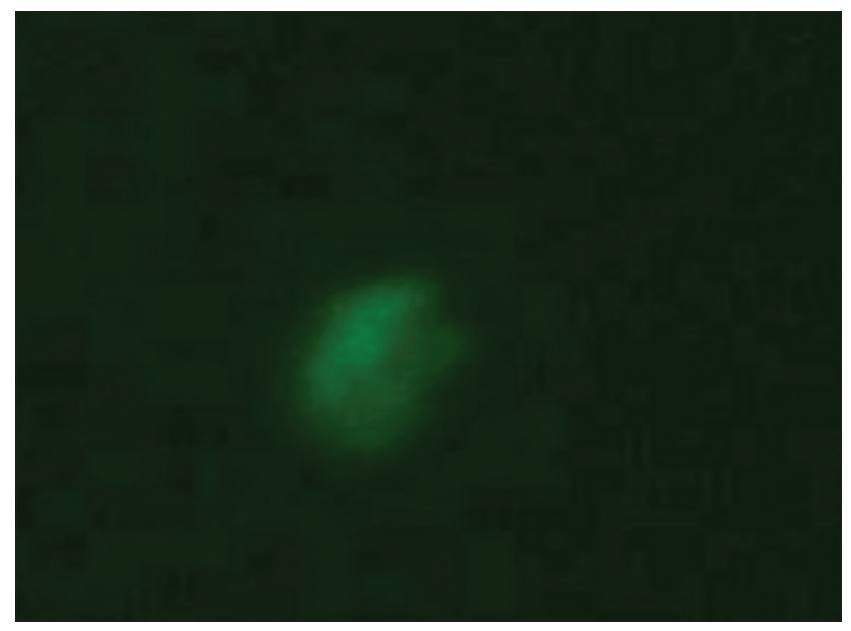

Figure 6: Immunofluorescence in CD34 expression

\section{Discussion}

In this study, analyses indicated that there was a significant difference in EPC proliferation with the administration of allicin, shown by an increase in proliferation in the treatment group compared to the control group. These results were in accordance with the previous studies by Zhang and Guo who reported that the administration of allicin could increase EPC proliferation activities through regulation of vascular endothelial growth factor (VEGF) and stromal cellderived factor (SDF)-1 expression [7]. Another in vitro studies from Li et al. also showed the same results, which found an increase in proliferation of cells by administering allicin at doses of $10-40 \mu \mathrm{g} / \mathrm{ml}$, but at higher doses, proliferation activity decreased. It is said that this increase in proliferation is caused by allicin being able to accelerate the cell cycle toward the S phase or synthesis phase [8].

The organosulfur component contained in allicin can activate the Akt and extracellular-regulated kinase (ERK) signal transduction pathways 1/2. Allicin will increase the expression and activity of cyclin D1 so that it will accelerate EPC to enter the $S$ cycle of the cell and increase EPC proliferation. The increase in Akt can activate mammalian target of rapamycin receptors found on EPC to increase its proliferation. In vivo, allicin can activate endothelial NO synthase (eNOS) and increase
NO bioavailability through the PI3K/Akt pathway so that it will inhibit the EPC apoptosis pathway and increase the amount [8], [9].

In allicin, there are various genes and are categorized based on their biological processes. The upregulated gene in allicin will produce a cellular response in the form of increased synthesis of adhesion molecules, increased expression of anti-apoptosis, and repair of damaged cell surface receptors. However, if a cell has the potential to proliferate without control, then the downregulation gene in allicin will inhibit the cell's signal transduction. Upregulated genes in allicin include glutamate-cysteine ligase modifier (GCLM); $\mathrm{HO}-1$; thioredoxin reductase 1 and 2; SLC7A11 (xCT); and DUSP1 (MKP1). Allicin can easily penetrate and enter through the cell membrane from EPC by diffusion toward the intracellular and conjugate with the thiol group from glutathione (GSH) to form global surgery student alliance (GSSA). The formation of GSSA together with the GCLM gene will increase intracellular GSH levels to 8-15-fold [10], [11]. Increased GSH levels will also increase telomerase activity, so cell proliferation will also increase. Aging and apoptosis in EPC which leads to rapid progression of atherothrombosis occur when GSH levels are low due to the inactivation of telomerase [12]. The results of this study reinforce the notion that allicin can directly influence EPC proliferation in vitro.

The previous research from Oommen et al. and $\mathrm{Li}$ et al. explained that allicin ability to increase EPC proliferation turned out to be in line with increasing dose, concentration, and time. EPC proliferation will be optimal by giving allicin a dose of $40-50 \mu \mathrm{g} / \mathrm{ml}$, but at doses above $50 \mu \mathrm{g} / \mathrm{ml}$, it will cause condensation from the cell nucleus and form apoptotic bodies which are characteristic of apoptosis [8], [13]. In this study, we had similar results, in which low, moderate, and high doses can increase EPC proliferation.

EPC has the ability to migrate to form a colony. Colony counts describe the cumulative characteristics of EPC quantities and functions including differentiation, proliferation, aging, and migration activities [14]. Interestingly in this study, there were fewer colonization results compared to controls in low-dose allicin, but the number of colonies increased in the administration of high-dose allicin. Until now, there have been no studies explaining the effects of giving allicin to the formation of EPC colonies. It is known that the EPC migration process to approach each other and form colonies is influenced by many factors. Various kinds of mediators such as eNOS and NO and chemokine-chemokine which are chemoactive such as SDF-1, lipid mediators (sphingosine-1 phosphate), and MCP-1 or interleukin can increase EPC migration [14], [15]. Because allicin works in a dose, concentration, and time-dependent manner, it is possible that at high doses, it can increase the ability of EPC migration through increasing VEGF expression. However, the CFU examination in this study was only done once as a confirmation that cultured 
EPCs can grow well without directly assessing whether

EPC has a good function for differentiation.

Increased EPC proliferation with allicin administration has been proven in this study. The effects of allicin both directly and indirectly through the mechanism of cytokine activation can increase the amount and proliferation of EPC. It is allicin effect on EPC proliferation that might explain the effects of improvement in cardiovascular disease.

This research still has many limitations. The mechanism of the influence of allicin on EPC proliferation was not examined in this study. This study only proves the existence of a direct effect of allicin on the proliferation of EPC regardless of all processes of balance in the body. Further research on the mechanism of EPC proliferation through the ERK 1/2, Akt, and GSH and telomerase activities still needs to be done. This research is still carried out in vitro. To confirm the effect of allicin in patients with SCAD, it still requires research in vivo. The slight difference in results with the previous studies also needs to be confirmed by further research with bigger sample sizes. In addition, further research is needed regarding the dose of lethal allicin so that it can be used to find out at what dosage allicin can increase proliferation or even pro-apoptosis.

\section{Conclusion}

Administration of allicin is proven to increase EPC proliferation in peripheral blood of SCAD patients. There is a significant difference in EPC proliferation in patients with SCAD where the increase in EPC proliferation is in line with increasing doses that show the dose-dependent effect of allicin. However, further research is needed using a larger number of samples to confirm the effect of allicin administration on proliferation and apoptosis of EPC. Further research on signal transduction pathways which causes EPC proliferation is also needed.

\section{References}

1. Tardif JC. Coronary artery disease in 2010. Eur Hear J Suppl 2010;12 Suppl C: C2-10. https://doi.org/10.1093/eurheartj/ suq014

2. Shantsila E, Watson T, Lip GY. Endothelial progenitor cells in cardiovascular disorders. J Am Coll Cardiol. 2007;49(7):741-52 PMid:17306702

3. Khakoo AY, Finkel T. Endothelial progenitor cells. Annu Rev Med. 2005;56:79-101. https://doi.org/10.1146/annurev. med.56.090203.104149

PMid: 15660503

4. Ginter E, Simko V. Garlic (Allium sativum L.) and cardiovascular diseases. Bratisl Lek Listy. 2010;111(8):452-6.

PMid:21033626

5. Hosseini M, Shafiee SM, Baluchnejadmojarad T. Garlic extract reduces serum angiotensin converting enzyme (ACE) activity in nondiabetic and streptozotocin-diabetic rats. Pathophysiology. 2007;14(2):109-12. https://doi.org/10.1016/j. pathophys.2007.07.002

PMid: 17875387

6. Ding G, Zhao J, Jiang D. Allicin inhibits oxidative stress-induced mitochondrial dysfunction and apoptosis by promoting PI3K/AKT and CREB/ERK signaling in osteoblast cells. Exp Ther Med. 2016;11(6):2553-60. https://doi.org/10.3892/etm.2016.3179 PMid:27284348

7. Zhang FX, Guo WS. Effect of allicin on proliferation activity and migration ability of human peripheral blood endothelial progenitor cells. Chin J Biol. 2014;27(2):202-6.

8. Li T, Shi HY, Hua YX, Gao C, Xia Q, Yang G, et al. Effects of allicin on the proliferation and cell cycle of chondrocytes. Int $\mathrm{J}$ Clin Exp Pathol. 2015;8(10):12525-32.

PMid:26722440

9. Chiang EP, Chiu SC, Pai MH, Wang YC, Wang FY, Kuo YH, et al. Organosulfur garlic compounds induce neovasculogenesis in human endothelial progenitor cells through a modulation of MicroRNA 221 and the PI3-K/Akt signaling pathways. J Agric Food Chem. 2013;61(20):4839-49. https://doi.org/10.1021/ jf304951p PMid:23663050

10. Horev-Azaria L, Eliav S, Izigov N, Pri-Chen S, Mirelman D, Miron $\mathrm{T}$, et al. Allicin up-regulates cellular glutathione level in vascular endothelial cells. Eur J Nutr. 2009;48(2):67-74. https:// doi.org/10.1007/s00394-008-0762-3

PMid: 19048328

11. Miron $T$, Rabinkov A, Mirelman D, Wilchek $M$, Weiner $L$. The mode of action of allicin: Its ready permeability through phospholipid membranes may contribute to its biological activity. Biochim Biophys Acta. 2000;1463(1):20-30. https://doi. org/10.1016/s0005-2736(99)00174-1

PMid:10631291

12. Pallardó FV, Markovic J, García JL, Viña J. Role of nuclear glutathione as a key regulator of cell proliferation. Mol Aspects Med. 2009;30(1-2):77-85. https://doi.org/10.1016/j. mam.2009.01.001

PMid:19232542

13. Oommen S, Anto RJ, Srinivas G, Karunagaran D. Allicin (from garlic) induces caspase-mediated apoptosis in cancer cells. Eur J Pharmacol. 2004;485(1-3):97-103. https://doi. org/10.1016/j.ejphar.2003.11.059

PMid:14757128

14. Isner JM, Asahara T. Angiogenesis and vasculogenesis as therapeutic strategies for postnatal neovascularization. J Clin Invest. 1999;103(9):1231-6. https://doi.org/10.1172/jci6889 PMid:10225965

15. UrbichC,DimmelerS. Endothelial progenitorcells: Characterization and role in vascular biology. Circ Res. 2004;95(4):343-53. https:// doi.org/10.1161/01.res.0000137877.89448.78

PMid:15321944 